\title{
EMPREGO DE HERBICIDAS DO GRUPO DAS URÉIAS SUBSTITUIDASS NA CULTURA DA CENOURA (Daucus carota L.). II - EFEITOS DOS HERBICIDAS SOBRE A CULTURA
}

\author{
ANTONIO AUGUSTO LUCCHESI* \\ SALIM SIMÃO** \\ KEIGO MINAMI**
}

\begin{abstract}
RESUMO
\end{abstract}
Foi realizado no Campo Experimental do Setor de Horticultura da ESALQ, Piracicaba, um experimento no sentido de verificar os efeitos de linuron, clorobromuron e cloroxuron sobre a cultura da cenoura. Foram testadas as dosagens mínima e máxima recomendadas pelos produtores dos herbicidas, em pré e pós-emergência das plantas daninhas.

Os herbicidas não interferiram na parte aérea da cenoura. Em geral, os tratamentos em pré-emergência deram maior produção de parte aérea, raízes e raízeș comerciáveis que os tratamentos em pós-emergência.

Tanto o linuron como o clorobromuron deram bons resultados, sem interferir na produção, enquanto que a dosagem mínima de cloroxuron deu menos produção, devido ao pequeno controle das plantas daninhas.

\section{INTRODUÇÃO}

O emprego de herbicidas nas culturas vem se expandindo cada vez mais devido ao custo da capina, escassez de mão-de-obra e economia de tempo. Porém, nem sempre a sua utilização é satisfatória para a cultura, podendo causar toxidez ou simplesmente reduzir a sua produção.

Os herbicidas do grupo das uréias têm sido indicados para a cultura da cenoura e é sabido que, para o controle de plantas daninhas, é relativamente eficiente. Porém, pouco se sabe sobre o seu efeito sobre a cultura, nas nossas condições.

O presente trabalho tem por finalidade comparar os efeitos de alguns herbicidas do grupo das uréias substituídas sobre a cultura de cenoura.

\section{REVISÃO DA LITERATURA}

Dentre os herbicidas recomendados para a cenoura, o linuron tem tido o melhor sucesso pela sua alta seletividade a essa cultura. No entanto, tanto a temperatura alta, a irrigação antes da aplicação do herbicida ou sombreamento, podem levar a cenoura a se tornar sensivel ao linuron (KURATLE e RAHN, 1968).

\footnotetext{
Entregue para publicação em 4/12/1975.

* Departamento de Botânica - ESALQ/USP.

** Departamento de Agricultura e Horticultura - ESALQ/USP.
} 
A seletividade do linuron à cenoura se deve às diferenças na absorção, me tabolismo e fitotoxidez de derivados metabólicos do linuron com relação à cenoura e outras plantas suscetíveis ao linuron (KURATLE, RAHN e WOODMANSEE, 1969).

No Brasil, LEIDERMAN e KRAMER (1966) e FORSTER e DEUBER (1971) estudaram o comportamento de alguns herbicidas do grupo das uréias na cultura da cenoura e obtiveram bons resultados no controle de plantas daninhas.

Recentemente, LUCCHESI, SIMÃO e MINAMI (1974) estudaram translocação de linuroun, cloroxuron e clorobromuron no solo em cultura de cencura.

\section{MATERIAL E MÉTODO}

O experimento foi conduzido no Campo Experimental do Setor de Horticultura da ESALQ, Piracicaba - SP, em solo argiloso e rico em matéria orgânica, com perfeita drenagem.

A cultivar testada foi a "Kuroda" e a condução da cultura foi de acordo com as técnicas recomendadas, com 2 desbastes de plantas, deixando-se uma planta a cada $4 \mathrm{~cm}$, na linha. Foram usadas 60 plantas por parcela, dentro de duas linhas úteis.

Os herbicidas utilizados foram:

a - linuron, pó molhável, $50 \%$ i.a.;

b - cloroxuron, pó molhável, $50 \%$ i.a.;

c-clorobromuron, pó molhável, $50 \%$ i.a.

Foram testadas duas épocas de aplicação: em pré e pós-emergência das plantas daninhas, em duas dosagens, a mínima e a máxima, recomendadas pelos produtores.

$O$ experimento foi em delineamento inteiramente casualizado em parcelas subdivididas, com três repetições.

Foram utilizados canteiros de $20 \times 1,80 \mathrm{~m}$, subdivididos em parcelas de $1,60 \mathrm{x}$ $1,60 \mathrm{~m}$, num total de 48 parcelas. Dentro de cada parcela, a área útil foi de $1,25 \mathrm{x}$ $0,40 \mathrm{~m}$, distanciadas $1,20 \mathrm{~m}$ uma da outra.

Os tratamentos, tanto $\mathrm{em}$ pré como em pós-emergência, foram os seguintes:

$\mathrm{L}_{1}=2 \mathrm{~kg} / \mathrm{ha}$ de linuron

$\mathrm{L}_{2}=4 \mathrm{~kg} / \mathrm{ha}$ de linuron

$\mathrm{B}_{1}=2 \mathrm{~kg} / \mathrm{ha}$ de clorobromuron

$\mathrm{B}_{2}=3 \mathrm{~kg} / \mathrm{ha}$ de clorobromuron

$\mathrm{C}_{1}=6 \mathrm{~kg} / \mathrm{ha}$ de cloroxuron

$\mathrm{C}_{2}=10 \mathrm{~kg} / \mathrm{ha}$ de cloroxuron

$\mathrm{L}=$ testemunha no "limpo", com retiradas das plantas daninhas feitas mensalmente.

$\mathrm{S}=$ testesmunha no "sujo" onde se deixaram as plantas daninhas proliferarem até o final da cultura.

Foram coletados os seguintes dados:

a - peso da matéria seca da parte aérea da cenoura; 
b - peso da matéria fresca total das raízes;

c - número e peso médio das raízes, classificadas em três tamanhos: pequenas (até $8 \mathrm{~cm}$ ); médias (8 a $12 \mathrm{~cm}$ ) e grandes (acima de $12 \mathrm{~cm}$ ) (KOYAMA et al., 1970).

\section{RESULTADOS}

Os resultados do peso da matéria seca da parte aérea da cenoura, em $\mathrm{g} / \mathrm{m}^{2}$ de canteiro, nos tratamentos de pré e pós-emergência, encontram-se no Quadro 1; os resultados do peso da matéria fresca total das raízes de cenoura, em $\mathrm{g} / \mathrm{m}^{2}$ de canteiro, nos tratamentos de pré e pos-emeıtência, encontram-se no i (uadro 2 e us resultados do peso das raízes comerciais de cenoura (médias + grandes) $\mathrm{em} \mathrm{g} / \mathrm{m}^{2}$ de canteiro, nos tratamentos de pré e pós-emergência, encontram-se no Quadro 3.

QUADRO 1 - Peso da matéria seca da parte aéreá da cenoura, em $\mathrm{g} / \mathrm{m}^{2}$ de canteiro, nos tratamentos de pré e pós-emergência.

\begin{tabular}{|c|c|c|c|c|c|c|}
\hline \multirow[t]{2}{*}{ Tratamentos } & \multicolumn{3}{|c|}{$\begin{array}{c}\text { Repetições } \\
\text { Pré-Emergência } \\
\end{array}$} & \multicolumn{3}{|c|}{$\begin{array}{c}\text { Repetições } \\
\text { Pós-Emergência }\end{array}$} \\
\hline & I & II & III & I & II & IIII \\
\hline $\mathrm{L}_{1}$ & 343,6 & 405,0 & 422,6 & 346,6 & 385,0 & 288,4 \\
\hline $\mathrm{L}_{2}$ & 430,8 & 456,4 & 397,2 & 411,0 & 223,2 & 204,6 \\
\hline $\mathrm{B}_{1}$ & 296,0 & 344,6 & 289,0 & 296,6 & 387,0 & 322,8 \\
\hline $\mathrm{B}_{2}$ & 423,0 & 370,8 & 225,0 & 375,0 & 345,0 & 245,0 \\
\hline $\mathrm{C}_{1}$ & 258,8 & 331,0 & 277,0 & 278,0 & 283,0 & 246,0 \\
\hline $\mathrm{C}_{2}$ & 362,4 & 337,4 & 305,6 & 222,8 & 268,0 & 309,0 \\
\hline$L^{2}$ & 405,6 & 444,6 & 462,8 & 296,4 & 350,4 & 430,6 \\
\hline$\overline{\mathbf{S}}$ & 244,8 & 70,4 & 105,0 & 33,0 & 153,0 & 64,8 \\
\hline
\end{tabular}

D.M.S. $(5 \%)=116,32 \mathrm{~g} \mathrm{e} \mathrm{C.V.}=19,45 \%$

QUADRO 2 - Peso da matéria fresca total das raízes de cenoura, em $\mathrm{g} / \mathrm{m}^{2}$ de canteiro, nos tratamentos de pré e pós-emergência.

\begin{tabular}{|c|c|c|c|c|c|c|}
\hline \multirow[t]{2}{*}{ Tratamentos } & \multicolumn{3}{|c|}{$\begin{array}{c}\text { Repetições } \\
\text { Pré-Emergência }\end{array}$} & \multicolumn{3}{|c|}{$\begin{array}{c}\text { Repetições } \\
\text { Pós-Emergência }\end{array}$} \\
\hline & I & II & III & I & II & III \\
\hline $\mathrm{L}_{1}$ & 2204 & 3428 & 3784 & 2721 & 2677 & 1870 \\
\hline $\mathrm{L}_{2}$ & 3060 & 4077 & 3229 & 2423 & 1718 & 1830 \\
\hline $\mathrm{B}_{1}$ & 2462 & 3666 & 2477 & 2238 & 2126 & 2876 \\
\hline $\mathrm{B}_{2}$ & 3318 & 3112 & 2243 & 2134 & 2556 & 1704 \\
\hline $\mathrm{C}_{1}$ & 2179 & 2016 & 2356 & 2606 & 2733 & 1321 \\
\hline $\mathrm{C}_{2}$ & 2762 & 3171 & 2423 & 1968 & 1652 & 1889 \\
\hline L & 3754 & 3907 & 2995 & 3102 & 2834 & 3148 \\
\hline $\bar{S}$ & 244 & 185 & 151 & 175 & 256 & 160 \\
\hline
\end{tabular}

D.M.S. $(5 \%)=844,34 \mathrm{~g} \mathrm{e} \mathrm{C.V.}=19,17 \%$ 
QUADRO 3 - Peso das raízes comerciáveis de cenoura (médias + grandes), em $\mathrm{g} / \mathrm{m}^{2}$ de canteiro, nos tratamentos de pré e pós-emergência.

\begin{tabular}{|c|c|c|c|c|c|c|}
\hline \multirow[t]{2}{*}{ Tratamentos } & \multicolumn{3}{|c|}{$\begin{array}{c}\text { Repetiç̃oes } \\
\text { Pré-Emergência }\end{array}$} & \multicolumn{3}{|c|}{$\begin{array}{c}\text { Repetições } \\
\text { Pós-Emergência }\end{array}$} \\
\hline & I & II & III & I & II & III \\
\hline $\mathrm{L}_{1}$ & 1799 & 3100 & 3330 & 2371 & 2244 & 1302 \\
\hline $\mathbf{L}_{2}$ & 2600 & 3895 & 2804 & 1912 & 1261 & 1386 \\
\hline$B_{1}$ & 2081 & 3416 & 2050 & 1694 & 1752 & 2490 \\
\hline $\mathrm{B}_{2}$ & 3154 & 2850 & 1805 & 1789 & 2301 & 1310 \\
\hline $\mathrm{C}_{1}$ & 1066 & 1403 & 1874 & 1834 & 2390 & 660 \\
\hline $\mathrm{C}_{2}$ & 2501 & 2975 & 1798 & 1696 & 1350 & 1341 \\
\hline$L^{2}$ & 3520 & 3641 & 2474 & 2680 & 2490 & 2676 \\
\hline
\end{tabular}

D.M.S. $(5 \%)=993,90 \mathrm{~g}$ e C.V. $=24,21 \%$

\section{DISCUSSÃO}

LEIDERMAN e KRAMER (1966) e FORSTER e DEUBER (1971), também obtiveram bons resultados com a utilização do herbicida linuron em cultura de cenoura.

Com relação à parte aérea da cenoura, constou-se que não houve diferença de peso seco entre a testemunha "no limpo" e os tratamentos efetuados com os três herbicidas, com exceção da dosagem mínima de cloroxuron $\left(\mathrm{C}_{1}\right)$ onde o mato desenvolveu-se mais. $\mathrm{Na}$ testemunha "no sujo", a parte aérea da cenoura teve pequeno desenvolvimento. Com relação às épocas de aplicação, houve maior produção nos tratamentos de pré-emergência.

Analisando-se a matéria fresca total de cenoura, ou seja, a produção total de cenoura, sem a parte aérea, constatou-se que não houve diferença entre a testemunha "no limpo" e os tratamentos realizados com linuron e clorobromuron. 0 cloroxuron mostrou-se menos eficiente. Constatou-se maior produção nos tratamentos de pré-emergência.

As análises de peso e número de raízes comerciais indicaram que não houve diferença dentre a testemunha "no limpo" e os tratamentos com os três herbicidas, com exceção da dosagem mínima de cloroxuron $\left(\mathrm{C}_{1}\right)$, onde a produção foi significativamente menor. Nas parcelas deixadas "no sujo", não houve produção de raízes comerciais. Nos tratamentos de pré-emergência, houve maior produção do que. nos de pós-emergência.

Com relação ao peso médio das raízes de cenouras pequenas, médias e grandes, constatou-se que não houve diferença entre os tratamentos e também entre as épocas de aplicação, com exceção das raízes médias onde a produção foi maior nos tratamentos de pré-emergência. Na testemunha "no sujo", constatou-se apenas raízes pequenas.

Nos tratamentos de pós-emergência, verificou-se que a concorrência feita pelo mato, no início do desenvolvimento da cultura, afetou-a, e a produção final foi menor que nos ţratamentos de pré-emergência. Esse fato concorda com os experimentos realizados por SHADBOLT e HOLM (1965) e BLANCO e OLIVEIRA (1971) que verificaram a existência de um período crítico de competição, que vai da emergência da cenoura até aos 25 dias subseqüentes. 
Constatou-se também, nos tratamentos de pós-emergência, que a utilização das dosagens máximas dos herbicidas, interferiu no desenvolvimento normal da cenoura, refletindo em menores produções quando comparadas às das dosagens mínimas. Isso decorre, da possível interferência, que as maiores dosagens possam ter feito, interrompendo parte da fotossíntese nas folhas da cenoura, ainda tenras (CAMARGO et al., 1971).

\section{CONCLUSÃO}

Dos resultados obtidos pode-se concluir:

a - os herbicidas não interferiram no peso seco da parte aérea da cenoura;

$\mathrm{b}$ - os tratamentos em pré-emergência deram maior produção de parte aérea, raízes e raízes comerciáveis que os tratamentos em pós-emergência;

c - tanto o linuron como o clorobromuron deram bons resultados, sem interferir na produção, enquanto que a dosagem mínima de cloroxuron deu menos produção, devido ao pequeno controle das plantas daninhas;

d - em pós-emergência das plantas daninhas, a utilização das dosagens máximas interferiram no desenvolvimento normal da cenoura.

\section{SUMMARY}

\section{USE OF SUBSTITUTED UREA HERBICIDES ON CARROT (Daucus carota L.) CROP. II - EFFECTS OF HERBICIDES ON THE CROP}

It was conducted an experiment in the Experimental Field of Horticulture Section of ESALQ, Piracicaba, to verify the effects of linuron, chlorobromuron, and chloroxuron on carrot crop. It was tested the minimum and maximum rates recommended by herbicide productors in "pré" and post-emergence of weeds.

The herbicide did not interfy over carrot overground part. Generally, pre-emergence treatments gave higher production of overground part, roots and commercial roots than post-emergence treatments.

Both linuron and chlorobromuron gave good results, without interfy over production, while the minimum rate of chloroxuron gave the least production due to poor weed control. 


\section{LITERATURA CITADA}

BLANCO, H.G. e D. de A. OLIVEIRA, 1971. Duração do período de competição de plantas daninhas com a cultura da cenoura (Daucus carota L.). O Biológico, 37:3-7.

CAMARGO, P.N. de et al., 1971. Texto Básico de Controle Químico de Plantas Daninhas. ESALQ, USP, Piracicaba, SP, 3ạ ed. ampl. ilust., $431 \mathrm{pp}$.

FORSTER, R. e R. DEUBER, 1971. Comparação de herbicidas de diversos grupos químicos em Cenoura. XI Reunião Anual da Sociedade de Olericultura do Brasil, 11 a 17/julho, Piracicaba, $\mathrm{SP}$, resumo, $3 \mathrm{pp}$.

KOYAMA, I.Y.; Y. OKIMURA e N. MAKISHIMA, 1970. Hortaliças. IN Guia de Comercialização Rural: 152-164.

KURATLE, H. e E.M. RAHN, 1968. Weed control in carrots with linuron and prometryne. Proc. Amer. Soc. Hort. Sci., 92:465-472.

KURATLE, H.; E.M. RAHN e C.W. WOODMANSEE, 1969. Basis for selectivity of linuron on carrot and common ragweed. Weed Science, 17:216-219.

LACHMAN, W.H., 1944. The use of oil sprays as seletive herbicides for carrots and parsnip. Amer. Soc. Hort. Sci. Proc., 45:445-448.

LEIDERMAN, L. e M. KRAMER, 1966. Controle de ervas daninhas em cenouras com herbicidas residuais. O Biológico, 32(3):43-48.

LUCCHESI, A.A.; S. SIMÃO e K. MINAMI, 1974. Translocação de herbicidas do grupo das uréias substituídas no solo. Anais da ESALQ, $31: 449-454$.

SHADBOLT, C.A. e L.G. HOLM, 1965. Some quantitative aspects of weed competition in vegetable crops. Weeds, 4:111-113. 